by broncho-pneumonia, which obscured the diagnosis at first. In sucklings the intermittent attack often manifests itself in convulsions, and the regular type is not always so sharply defined as in the case reported, and especially the distinct division into stages is wanting.

- We learn by a recent exchange of the death, on September 25th, of Professor C. A. Wunderlich, of Leipzig, so well known from his work on Medical Thermometry. His affection was carcinoma of the retro-peritoneal glands, which he is said to have diagnosticated on himself in his clinic in 1876.

- The London Medical Record gives the following account of the researches of Faye on the secretion of milk in the new-born: He ascertained, from an examination of one hundred and twenty cases, that it was absent in six only, four being boys and two girls. The distribution of sexes in the others was nearly equal. In forty-five per cent. of the whole number it commenced on the fourth or fifth day; in the others, from the second to the tenth day, never later, never earlier. As a rule, the secretion begins with the fall of the umbilical cord, but the author denies the existence of any casual connection between the two, as the exceptions to this coincidence are suffciently numerous. The quantity of milk emitted is, in general, very small usually two or three drops. Genser, however, on one occasion expressed three grammes. When mastitis is produced the secretion often disappears. Milk was never found after the first five or six weeks. It is, as a rule, very alkaline, and resembles colostrum. Under the microscope it exhibits numerous granules and some fat-globules. The latter are ordinarily sparse, but occasionally are as numerous as in woman's milk. The analysis given by Genser is : casein, 0.56 ; albumen, 0.49 ; sugar, 0.96 ; fat, 1.46 ; salts, 0.83 ; water, 95.7. The author mentions further that the mammary gland of the male occasionally swells slightly at puberty, and may then contain one or more drops of a secretion resembling milk.

- The Philadelphia Medical Times for October 27, 1877, reports the success of the new plan of teaching at the university to be all that could be desired. There are one hundred and thirty first-course students entered for the three years, and the general paying class is as large as it was last year. The character of the class has much improved, the average intelligence and education of the new men being notably superior.

\title{
COLLEGE OF PHYSICIANS AND SURGEONS, NEW YORK.
}

\section{CLINIC OF PROF. T. GAILLARD THOMAS FOR DISEASES OF WOMEN.}

Oстовев 19, 1877. Slight Laceration of the Cervix Uteri.-Mrs. Anne G., a native of Poland, thirty years or age. She has been married for ten years, and has had five children, but no miscarriages. The patient gives us the following history: She was perfectly well in every respect up to the time of her last confinement, which occurred four years ago, but says she has never been well since. She complains of pain-in the head, back, side, and down the 
leg, and of cramps in the bowels extending around to the back; she attributes all her trouble to the fact that she got up too soon after her confinement and took cold from sitting near an open window. On questioning her more particularly as to the character of the headache, we find that it seems to amount really to hemicrania, and that the pain appears to shoot down the right side of the body as far as the thigh. The menstrual flow returns every three weeks, but is not too free in quantity. She experiences no unusual suffering just before it makes its appearance, and while it continues the pain above mentioned is very much relieved. Leucorrhœa usually follows the menstrual period. Now, as our patient is evidently not the kind of woman who would manufacture complaints, let us see if we can find out anything by a physical examination to account for the symptoms of which she tells us.

Placing the patient on the back, I discovered on inserting my finger into the vagina that there was a slight laceration of the cervix uteri. The two lips of the wound were separated to a very small extent, but cicatrization had taken place, and they were everywhere covered with mucous membrane. The uterus was apparently normal in size and position. It was perfectly movable and not at all sensitive, nor could I detect a prolapsed ovary or any other source of irritation about it. Then placing the patient on her side, $I$ introduced the probe, and ascertained positively that the uterus was in its natural position and that the canal was of the natural length. I may here explain that for the purpose of exploration I greatly prefer the light and flexible silver probe to the sound, and invariably use it unless there is some special reason for employing the latter. After the most thorough examination I was unable to discover anything abnormal whatever about any of the pelvic organs, except the old laceration of the cervix of which I have spoken. Now, have we discovered anything to account for the symptoms, or, in other words, made out a diagnosis? I tell you perfectly frankly that we have not, and that is the very poiut I want to make in this case, and the reason why I have brought the patient before you. A diagnosis is the discovery of a certain pathological cause for certain pathelogical symptoms noticed, and I would warn you never to fix upon some little epi-phenomenon, like this slight laceration of a cervix, and then declare that you have made out your diagnosis. I have made an examination with the greatest care, and have found absolutely nothing about the pelvic viscera to account for this woman's trouble. Just now, I am aware, laceration of the cervix is attracting a great deal of attention in gynæcological circles; but, as is always the tendency with new things, it seems likely to assume a great deal more importance than it really deserves. It is supposed to produce very much such symptoms as we have noticed here; yet I am utterly unable to see how a slight laceration like this can be followed by such results. Suppose that this patient were in private practice, and that I should perform an operation, and then that all the symptoms should continue just the same afterward; I do not think either she or myself would be very well satisfied. I will not treat her for uterine disease for the simple reason that $I$ have not found any. It is probable that she may have had subinvolution after her confinement, but if so, it has all passed away now. I will not attempt to make a diagnosis in this case, because it does not properly belong to our department, 


\section{College of Physicians and Surgeons, New York. [November 8,}

but will simply say that there seems to be some intestinal trouble, the nature of which I cannot now stop to find out definitely. I remember just such a case as this being presented at the clinic a few years ago, and a fortnight afterward the woman came back with a tape-worm thirty feet long which she had passed, and which, of course, accounted for all the symptoms. Yet she had been treated for years for uterine disease. Gynæcology is not without its enemies, and one great reason why it has enemies is that some of those who devote themselves to it make so much of trivial particulars; and it is to warn you against doing this that $I$ have occupied so much of your time with this case, notwithstanding the fact that $I$ have more interesting material outside than I can possibly present to you to-day. So I have made my point, though $I$ have not made a diagnosis.

Phantom Tumor; Retroflexion and Prolapsed Ovary. - Delia H., a native of Ireland, and twenty-nine years of age. She has been married eleven years and has had one child, but no miscarriages. The child was born ten years ago; yet though she has been living constantly with her husband she has never been pregnant since. She says that she was quite well up to three years ago, when she began to have a "heavy drag," as she expresses it, in the pelvic region, and a good deal of pain in the back, chest, and head. The menses occur every three weeks, and during the time of their appearance, which is usually about five days, she suffers excessively. She says she is in the habit of using peppermint to relieve the pain, but she has not been obliged to resort to opium, as far as we are able to learn. During the interval she is subject to leucorrhœa, and she tells us that she suffers greatly from weakness in walking. This is all the history that she has to give us. You observe how pale and anxious she looks, as if something had been wrong for a considerable time. One thing more: she regrets that she has never had any more children, and is at a loss how to account for this fact.

The per vaginam examination was made precisely as in the last case in order to see whether anything could be found to account for the symptoms complained of, and I should have been very greatly disappointed if we had not found something wrong there. The persistent pain in the back, the excessive dysmenorrhœe, and the sterility all pointed strongly towards the pelvic organs. In the other case, on the contrary, the principal symptoms, the hemicrania and the cramps in the abdomen, were quite irrelevant, and the only point of any value in this connection was the fact that the pain was relieved during the menstrual flow. Now what did our examination reveal? First of all the cervix was found in its normal position and with a slight laceration, as in the preceding case. But lacerations of this kind, I would have you understand, are the rule with women who have borne children, and not the exception. Such a little nick in the cervix is in reality physiological and not pathological, and is a very different matter, $I$ assure you, from a rent which is really entitled to be called a laceration, and which may undoubtedly be followed by serious consequences. After thus examining the cervix I carried my finger around to the back of the uterus, and there found a round and exceedingly tender mass of some size. Just anterior to it $I$ felt a distinct bend in the uterus, so that my finger could be carried into a little fossa, as it were. 
On external manipulation I discovered what appeared to be undoubtedly an ovarian cyst filling the whole abdomen. It was very firm and unyielding, but when percussion was made over it it gave every where a loud, drum-like resonance. At the present time you can hear this tympanitic sound distinctly, even through the patient's clothing. The tumor is perfectly globular in form, but contains nothing but air. In order to become assured of this fact I requested the patient to make a forced expiration, and at the same time pressed my hand firmly into the lower part of the abdomen. She repeated this four or five times, and each time I succeeded in pressing my hand still further in, until at last the fingers of this hand met those of the other passed into the vagina. There was, therefore, no trace of an ovarian cyst. Now if $I$ were not positively certain here, this would be just the case for testing by anæsthetization. It would be unnecessary in the present instance, and as the patient is in a very depreciated condition of health, and lives at a considerable distance, we will dispense with it. This, then, is a case of phantom tumor. These tumors are continually being mistaken for ovarian cysts, and patients are not infrequently sent two or three hundred miles for the purpose of having ovariotomy performed, greatly to their inconvenience and anxiety, and much to the physician's mortification when the true state of affairs becomes known. Now it is principally to prevent you from making such mistakes when you get into practice that $I$ bring this case before you. What will prevent you from sending such patients to have ovariotomy performed? Simply this : the reflection that no bag filled with water is resonant on percussion. You know how different the sound given out by a bladder filled with water is from that of one containing only air. These phantom tumors are nothing more than collections of gas accompanied by a kind of spasm of the abdominal muscles, which renders them very hard. If there is any shadow of a doubt, thoroughly anæsthetize your patient, when it will vanish, and the case be made perfectly clear.

But now let us consider a little more carefully what is the condition of affairs revealed by the examination per vaginam in this case. It might be that the mass which has been noted behind the cervix is a fibrous tumor, but in that case the fundus would be felt above on external palpation, and the probe or wound would indicate that the body of the organ is in its normal position or perhaps slightly anteverted. The fundus, however, cannot be thus felt, and the probe passes downwards and backwards with a pretty sharp bend. There is, then, a flexure of the uterus backward. But this is not all. The round, tense, and exceedingly sensitive mass which $I$ have spoken of behind and below the uterus can be nothing else than one of the ovaries which has fallen down into Douglas's cul-de-sac. The next question that arises is, Does the condition which we have found account for the symptoms noted? and the answer is, Yes, amply. The retroflexion, no doubt, occurred immediately after the confinement ten years ago, when the uterus was, large and heavy, and owing to the continuous engorgement of the organ the condition has gradually been growing more aggravated ever since. In addition there has been chronic ovaritis, and one of the ovaries, being much larger and beavier than in its normal condition, has gradually sunk lower and lower in the pelvis, 
until it has slipped into Douglas's pouch. This latter occurrence probably took place about three years ago, from which time she seems to date her troubles.

In the treatment the indications are to restore the uterus to its normal position and to push up the ovary out of the cul-de-sac into which it has fallen. While in its present constrained position it is kept in a continual state of irritation and hyperæsthesia by the act of coitus, the loaded rectum, and other such agencies, from which it is free when higher up in the pelvis. Of course this woman needs the best of care, and hers is just a legitimate case for the hospital, because we have a chance to do her a great deal of good by treatment. Her looks indicate that she has been living poorly, while she requires a generous and highly nutritious diet. Above all she needs rest, and $I$ think in two months from now, if she can be admitted to the Woman's Hospital, I can present her to you a very different looking woman from what she is to-day. A great deal of her trouble is undoubtedly due to the marked flexure of the uterus, which we have found to exist. This keeps the organ more or less engorged at all times, and at the monthly periods renders the escape of the menstrual blood exceedingly difficult, and thus gives rise to the obstinate dysmenorrhœa from which she suffers. The uterine canal in its present condition is very much like an India-rubber tube bent upon itself (so that no fluid can pass through it), and the simple indication is to straighten it, which, $\mathrm{I}$ cannot doubt, will result in the removal of the hyperæmia now existing, and the return of the organ to the normal fulfillment of its functions.

( $T$ o be continued.)

\section{ABUSE OF MEDICAL CHARITIES.}

Messrs. Editors, - I was much interested by the manly article on the Abuse of Medical Charities, by Dr. Rogers, in the last Journal, and with the editorial comments; and I hope your pages will be open to a full discussion of the subject. One point seems hardly to have been indicated, - the evil of panperizing the population by giving people what they can afford to pay for. Nor is it made plain that if the really destitute only were aided there would be any lack of material for thorough clinical work. It needs to be reiterated that relief to the poor is not grudged by the profession. I cannot see what the question of the "ins" and the "outs" has to do with the matter. If it be true that there is an immense amount of imposition upon medical charities, the " ins" and the "outs" must pull together with a will to detect it and to provide a remedy. 